\title{
Repository dan Evaluasi Framework Forensika Digital Menggunakan Daubert Criteria
}

\author{
Muzammilatul Wachidah ${ }^{1}$, Mukhammad Andri Setiawan $^{2}$, Yudi Prayudi $^{3}$ \\ 1,2,3) Magister Informatika, Fakultas Teknik Industri, Universitas Islam Indonesia \\ Email: ${ }^{1}$ 14917221@students.uii.ac.id, ${ }^{2}$ andri.setiawan@uii.ac.id, ${ }^{3}$ prayudi@uii.ac.id
}

(Naskah masuk:23 Desember 2019, diterima untuk diterbitkan: 6 Januari 2020)

\begin{abstract}
ABSTRAK
Terdapat banyak framework forensika digital masih tersebar dalam berbagai paper. Diperlukan sebuah upaya untuk menghimpun framework yang ada dalam sebuah repository untuk memudahkan mendapatkan informasi dan dokumentasi tentang framework tersebut. Selain itu, framework sebagai sebuah output dari kajian ilmiah perlu dilengkapi dengan review dari pakar agar bisa memberikan gambaran tentang framework tersebut dari sudut pandang pakar. Salah satu metode yang dapat digunakan untuk melakukan penilaian adalah menggunakan Daubert Criteria. Penelitian ini adalah sebuah upaya untuk menyiapkan sebuah system yang dapat menjadi repository framework dalam bidang forensika digital serta penilaian pakar terhadap framework tersebut. Adanya system ini diharapkan akan memudahkan untuk mendapatkan informasi tentang framework pada forensika digital serta menjadi media untuk mendapatkan dokumentasi tentang sehingga dibutuhkan sebuah repository untuk mendokumentasikannya. Sementara itu, evaluasi framework fframework yang dihasilkan oleh para penelitian melalui publikasi paper yang dapat diakses oleh publik.
\end{abstract}

Kata kunci: repository; framework forensika digital; evaluasi; daubert criteria; expert

\begin{abstract}
There are many digital forensics frameworks still scattered in various papers. An effort is needed to compile the existing framework in a repository to make it easier to get information and documentation about the framework. In addition, the framework as an output of scientific studies needs to be supplemented by reviews from experts in order to be able to provide an overview of the framework from the expert's point of view. One method that can be used to conduct assessments is to use Daubert Criteria. This research is an attempt to prepare a system that can become a repository framework in the field of digital forensics and expert assessment of the framework. The existence of this system is expected to make it easier to obtain information about the framework in digital forensics as well as being a reference to get documentation about the framework produced in the field of digital forensics research.
\end{abstract}

Keywords: repository; digital forensics framework; evaluation; daubert criteria; expert

\section{Pendahuluan}

Ciri utama dari forensik adalah scientific methods [1]. Hal ini berlaku pula untuk forensika digital. Selanjutnya, agar output forensika digital dan bukti digital dapat diterima dalam proses hukum, maka menurut [2] dan [3] terdapat beberapa kriteria yang harus dipenuhi antara lain: admissible, authentic, complete, reliable, dan believable. Khususnya untuk kriteria admissible (dapat diterima secara hukum), maka digunakan sebuah scientific methods yang dapat diterima secara hukum atau tidak. Kedua pendekatan tersebut dikenal Frye Standard dan Daubert Criteria.

Perdebatan dari aspek hukum, tentang mana yang lebih relevan untuk diterapkan dalam menentukan apakah scientific methods agar dapat diterima secara hukum 
telah dijelaskan [4]. Dalam hal ini Frye Standard menggunakan prinsip "generally accepted in relevant scientific community", sementara Daubert Criteria menerapkan prinsip "scientifically valid based on fact and data". Sesuai dengan karakteristik digital yang relatif sangat cepat perkembangannya, maka bidang forensika digital lebih tepat menerapkan prinsip Daubert Criteria dibandingkan dengan Frye Standard [5].

Tujuan dari Daubert adalah untuk menegaskan aturan-aturan dari penjelasan penyidik (expert) dan untuk mengeliminasi junk science di pengadilan [6][7]. Daubert merujuk pada testability, peer review and publication, error rate, standards control dan general acceptance.

Hakim bertindak sebagai "gatekeeper", yang menentukan diterima atau tidaknya penjelasan expert di pengadilan [6]. Berdasarkan survey (data sampel $=400$ ), hakim sangat mendukung posisi sebagai "gatekeeper" yang dibuat oleh Daubert.

Investigator memerlukan framework forensika digital dalam menyelesaikan kasus yang sedang ditangani. Framework forensika digital akan menjadi panduan mengenai bagaimana cara mengolah barang bukti digital. Untuk saat ini, framework forensika digital masih tersebar dalam berbagai paper. Hal ini tentunya mempersulit investigator dalam mencari data dan informasi terkait framework forensika digital tersebut, sehingga akan memperlambat kinerja investigator. Untuk itu, dibutuhkan sebuah repository forensika digital sebagai wadah untuk mendokumentasikan framework forensika digital.

Untuk menangani sebuah kasus, investigator harus dapat memilih framework forensika digital yang tepat. Investigator biasanya memilih framework forensika digital untuk kasus yang sedang ditangani berdasarkan rekomendasi dari rekan atau dengan cara bertanya dalam forum forensika digital. Walaupun demikian, masih ada 30\% investigator yang tidak yakin dengan framework forensika digital yang dipilih untuk menyelesaikan kasus yang sedang ditangani. Untuk iu dibutuhkan sebuah evaluasi framework forensika digital yang dilakukan oleh orang yang berkompeten sehingga dapat memudahkan investigator dalam memilih framework forensika digital yang akan dipilih.

Maka dari itu diperlukan sebuah penelitian yang berfokus pada repository dan evaluasi framework forensika digital menggunakan Daubert Criteria.

\section{KAJIAN PUSTAKa}

\section{A. Repository}

Repository framework adalah sebuah wadah untuk mendokumentasikan berbagai framework forensika digital. Repository ini berguna untuk memberikan informasi mengenai detail framework forensika digital, sehingga memudahkan dalam pencarian informasi mengenai berbagai framework yang ada saat ini.

\section{B. Forensika Digital}

Forensika digital merupakan aktivitas yang berhubungan dengan pemeliharaan, identifikasi, pengambilan/penyaringan dan dokumentasi bukti digital dan kejahatan komputer [8].

Forensika digital merupakan penggunaan metode ilmiah terhadap pelestarian, validasi, identifikasi, analisis, interpretasi, dokumentasi dan presentasi bukti digital yang berasal dari sumbersumber digital untuk tujuan memfasilitasi atau melanjutkan rekonstruksi peristiwa tindak pidana atau membantu mengantisipasi tindakan yang tidak sah yang terbukti mengganggu operasi yang direncanakan [9]. 


\section{Daubert Criteria}

Daubert membuat empat non-eksklusif untuk diterima atau tidaknya testimoni dari expert. Factor yang spesifik diidentifikasi oleh Supreme Court diantaranya: (1) apakah teori yang digunakan oleh expert sudah dilakukan pengujian secara obyektif, tidak secara subyektif, untuk pendekatan yang tidak bisa diverifikasi; (2) apakah teori dari expert sudah melalui peer review atau publikasi; (3) apakah error rate dari teori yang digunakan expert sudah diketahui; (4) apakah teori yang diberikan expert diaplikasikan berdasarkan standar ata control tertentu; (5) apakah teori dari expert sudah diterima dalam komunitas akademik yang relevan.

Pada perkembangannya, factor eksklusif atau bukan tidak sepenuhnya mempengaruhi diterima atau tidaknya testimoni dari expert. Tidak semua faktor spesifik dari Daubert dapat diaplikasikan dalam setiap bentuk testimoni dari expert. Sebagai contoh, kurangnya peer review atau publikasi menjadi tidak penting asalkan opini sudah memenuhi "general acceptance".

Daubert standard menyediakan aturan bukti mengenai diterimanya kesaksian para saksi ahli di Amerika Serikat selama proses hukum federal. Penggunaan "Daubert Standard" dalam sistem peradilan di Amerika Serikat tidak seragam. Ada negara bagian yang tetap memakai Frye Test, ada pula yang memakai Daubert Standard dengan berbagai variasinya. Penerapan Daubert Standard secara penuh dilakukan di sembilan negara bagian. Negara bagian lain ada yang masih menggunakan Frye Test atau salah satu kombinasi dari Daubert Standard.

Daubert Criteria juga masih menggunakan keterangan dari saksi ahli akan tetapi tapi ada tim juri yang memberi penilaian dan masukan kepada hakim terhadap keterangan yang telah diberikan oleh saksi ahli tersebut.

Telah diusulkan sebuah metrik untuk menilai sejauh mana sebuah framework forensika digital telah memenuhi tuntutan sesuai dengan prinsip Daubert Criteria [10]. Metrik ini kemudian disempurnakan dan digunakan untuk memetakan beberapa framework forensika digital yang telah dikaji oleh berbagai peneliti lainnya [7]. Metrik ini menjadi pertimbangan bagi pihak berwenang untuk mendapatkan keyakinan sejauh mana keandalan dari framework tersebut dalam hal terpenuhinya aspek scientific methods.

Dalam hal ini terdapat 5 kriteria yang digunakan untuk assessment Daubert Criteria, yaitu:

1) Apakah teori atau teknik yang dimaksud dapat dan telah diuji (whether the theory or technique in question can be and has been tested).

2) Apakah teori atau teknik yang dimaksud telah melewati proses peer review dan publikasi (whether it has been subjected to peer review and publication).

3) Apakah teori atau teknik yang dimaksud diketahui kesalahannya (its known or potential error rate).

4) Adanya standard yang melakukan control terhadap pengoperasiannya (the existence and maintenance of standards controlling its operation), dan

5) Apakah memungkinkan untuk diterima secara luas oleh komunitas ilmiah yang relevan (whether it has attracted widespread acceptance within the relevant scientific community).

\section{Metodologi Penelitian}

Metodologi penelitian yang digunakan sebagaimana ditunjukkan oleh gambar berikut. 


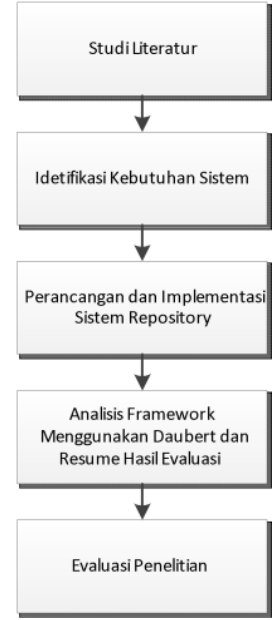

Gambar 3.1 Metodologi Penelitian

Untuk menerapkan metodologi penelitian, langkah pertama adalah melakukan studi literatur untuk mencari informasi yang dipelukan. Menyebarkan angket dibutuhkan untuk mengidentifikasi kebutuhan sistem. Selanjutnya, dibuatlah perancangan sistem untuk repository framework dan evaluasi framework menggunakan Daubert Criteria.

Use Case Diagram untuk sistem respository framework forensika digital sebagaimana ditunjukkan oleh Gambar 3.2.

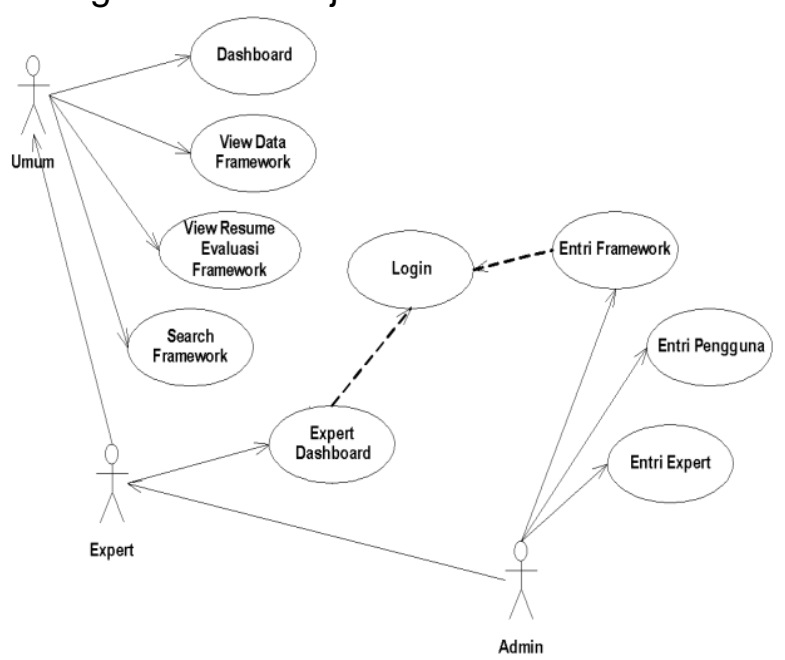

Gambar 3.2 Use Case Diagram Repository Framework

Pengguna dalam sistem repository dibedakan menjadi tiga, yaitu admin, expert, dan umum. Masing-masing pengguna memiliki hak akses yang berbeda. Admin melakukan login untuk memberikan entri data framework, pengguna dan expert. Dalam perancangan sistem, Activity Diagram untuk Admin dalam sistem respository framework forensika digital sebagaimana ditunjukkan oleh Gambar 3.3. Admin login untuk melakukan entri framework dan data expert.

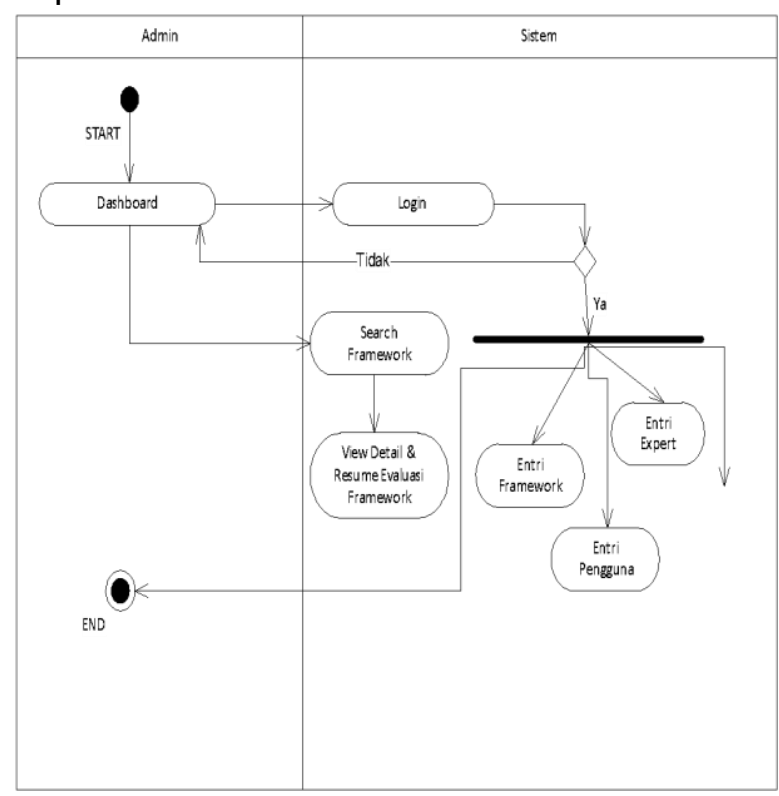

Gambar 3.3 Activity Diagram Admin dalam Repository

Sementara itu, expert dapat login setelah mendapatkan hak akses dari admin. Activity Diagram untuk Expert dalam sistem repository framework forensika digital sebagaimana ditunjukkan oleh Gambar 3.4. 


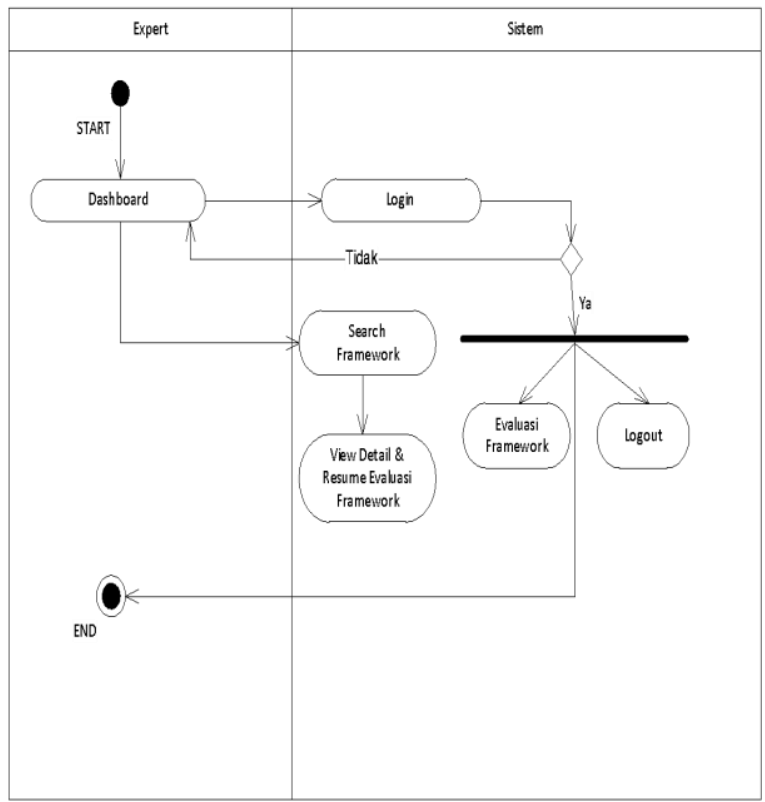

Gambar 3.4. Activity Diagram Expert dalam Repository

Pengguna Umum tidak mendapatkan akses untuk login, hanya dapat melihat data framework, resume evaluasi framework. Activity Diagram untuk Umum dalam sistem respository framework forensika digital sebagaimana ditunjukkan oleh Gambar 3.5.

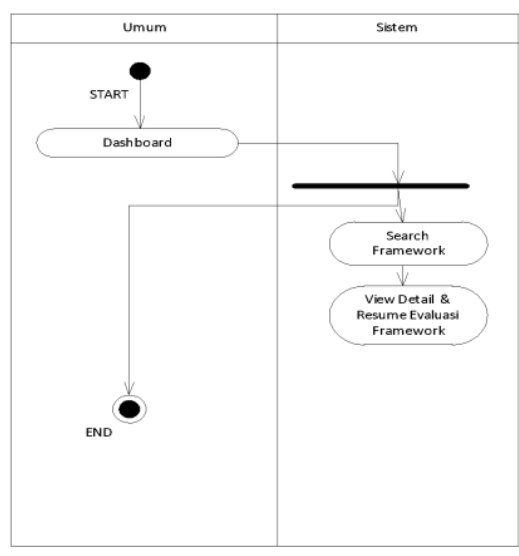

Gambar 3.5 Activity Diagram Umum dalam Repository

Perancangan evaluasi framework untuk Admin sama dengan sistem repository, hanya ada tambahan Admin menampilkan resume hasil evaluasi framework. Activity Diagram Admin sebagaimana ditunjukan oleh Gambar 3.6.

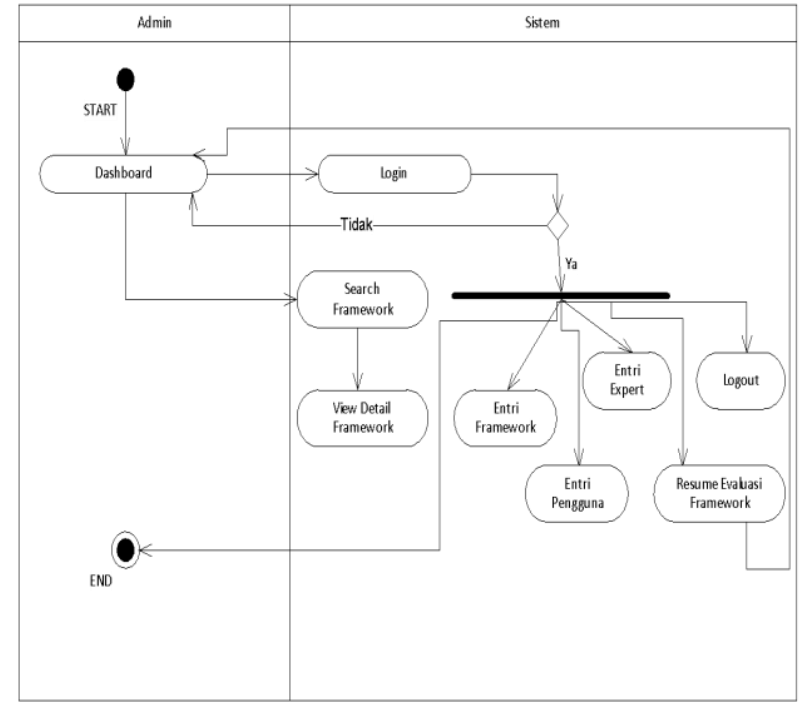

Gambar 3.6 Activity Diagram Admin dalam Evaluasi Framework

Untuk pengguna Expert, setelah login dapat memilih framework yang akan dievaluasi. Selanjutnya, Expert akan menunggu notifikasi dari Admin untuk melakukan evaluasi ulang jika ada hasil evaluasi framework yang tidak sama untuk satu kriteria Daubert. Activity Diagram untuk Expert dalam evaluasi framework forensika digital sebagaimana ditunjukkan oleh Gambar 3.7.

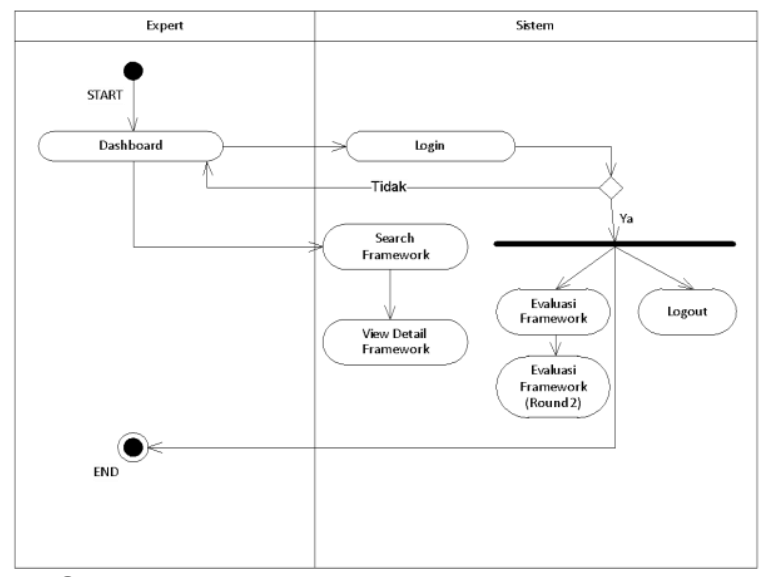

Gambar 3.7 Activity Diagram Expert dalam Evaluasi Framework

Pengguna Umum dalam sistem evaluasi framework forensika digital sama seperti repository. Perbedaannya adalah adanya tambahan untuk melihat resume hasil evaluasi. Activity Diagram untuk Umum 
dalam evaluasi framework forensika digital sebagaimana ditunjukkan oleh Gambar 3.8.

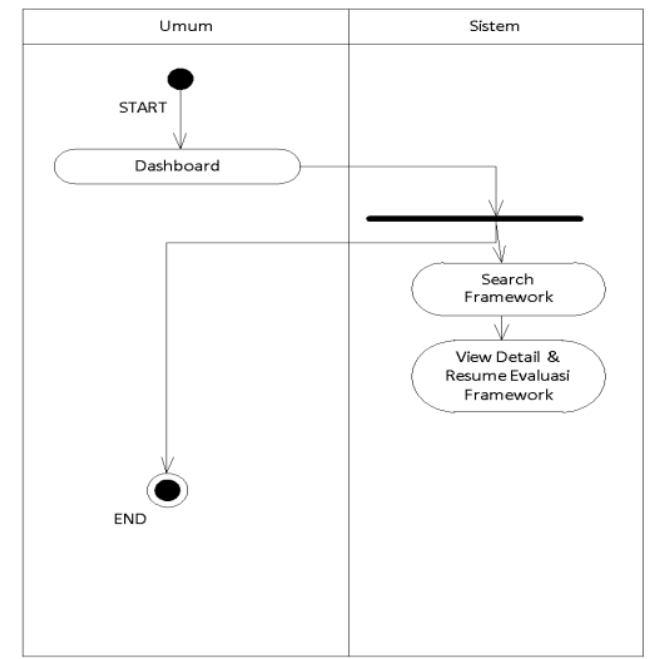

Gambar 3.8 Activity Diagram Umum dalam Evaluasi Framework

Setelah perancangan sistem sudah dibuat dan diimplementasikan, langkah selanjutnya adalah melakukan analisis framework forensika digital. Evaluasi framework dilakukan dengan menggunakan Daubert Criteria, dengan melakukan pengujian terhadap lima kriteria dari Daubert Criteria. Acuan diterimanya kriteria untuk setiap evaluasi dapat dilihat pada Tabel I.

TABEL I. TABEL ACUAN KRITERIA

\begin{tabular}{|c|c|c|}
\hline $\begin{array}{l}\mathbf{N} \\
\mathbf{0}\end{array}$ & Kriteria & Acuan Kriteria \\
\hline 1 & $\begin{array}{l}\text { Apakah teori/teknik } \\
\text { yang dimaksud dapat } \\
\text { dan telah diuji. }\end{array}$ & $\begin{array}{l}\text { Terdapat informasi bahwa } \\
\text { model tersebut telah diuji / } \\
\text { diimplementasikan pada } \\
\text { lingkungan yang relevan. }\end{array}$ \\
\hline 2 & $\begin{array}{l}\text { Apakah teori atau } \\
\text { teknik yang dimaksud } \\
\text { telah melewati proses } \\
\text { peer review dan } \\
\text { publikasi }\end{array}$ & $\begin{array}{l}\text { Terdapat informasi yang } \\
\text { menyatakan bahwa model } \\
\text { yang dimaksud telah } \\
\text { mengalami proses peer } \\
\text { review dan publikasi ilmiah. }\end{array}$ \\
\hline 3 & $\begin{array}{lr}\text { Apakah teori/teknik } \\
\text { yang dimaksud } \\
\text { diketahui } \\
\text { kesalahannya }\end{array}$ & $\begin{array}{l}\text { Apabila model telah } \\
\text { diimplementasikan /diuji } \\
\text { cobakan maka diketahui } \\
\text { potensi kesalahannya. }\end{array}$ \\
\hline 4 & $\begin{array}{l}\text { Adanya standard yang } \\
\text { melakukan kontrol } \\
\text { terhadap } \\
\text { pengoperasiannya }\end{array}$ & $\begin{array}{l}\text { Terdapat informasi yang } \\
\text { menyatakan bahwa model } \\
\text { yang dimaksud } \\
\text { dibangun/dioperasikan } \\
\text { didasarkan pada standard } \\
\text { tertentu untuk } \\
\text { menjalankannya }\end{array}$ \\
\hline 5 & $\begin{array}{l}\text { Apakah } \\
\text { memungkinkan untuk }\end{array}$ & $\begin{array}{l}\text { Terdapat informasi yang } \\
\text { menyatakan bahwa model }\end{array}$ \\
\hline
\end{tabular}

\begin{tabular}{ll}
\hline $\begin{array}{l}\text { diterima secara luas } \\
\text { oleh komunitas ilmiah }\end{array}$ & $\begin{array}{l}\text { telah diterima secara luas } \\
\text { dalam komunitas forensika } \\
\text { yang relevan. }\end{array}$ \\
\hline
\end{tabular}

Teknis pemberian evaluasi framework forensika digital berdasarkan Daubert Scoring adalah sebagai berikut:

- Mempelajari paper terkait dengan framework yang sedang dievaluasi.

- Memahami data dan fakta untuk setiap kriteria melalui proses pencarian informasi yang relevan.

- Argumen dapat bersifat subjektif ataupun objektif tergantung dari informasi primer/sekunder yang didapat atau melalui informasi yang termuat dalam referensi lainnya.

Untuk masing-masing kriteria, yang harus diisi oleh expert adalah sebagai berikut:

a. Data dan fakta, berisi fakta apa saja yang menunjukkan bahwa kriteria tersebut terpenuhi oleh framework.

b. Argumen, berisi data pendukung (tambahan) yang diberikan oleh expert.

c. Terpenuhi/tidak, merupakan opsi terpenuhi atau tidaknya kriteria dari sebuah framework forensika digital. Ini akan mempengaruhi hasil dari Daubert Scoring dari masing-masing framework.

Expert memberikan evaluasi framework forensika digital berdasarkan semua kriteria dalam Daubert. Setelah minimal ada tiga expert yang memberikan evaluasi, selanjutnya dilakukan pengecekan hasil evaluasi. Jika ada sebuah kriteria dengan evaluasi framework yang berbeda antar expert, maka evaluasi akan masuk pada tahap Round 2. Pada Round 2 ini, expert yang akan melakukan evaluasi ulang untuk kriteria Daubert tersebut. Setelah itu dilakukan pengecekan ulang untuk evaluasi ulang yang dilakukan oleh expert. jika hasil akhirnya menunjukkan bahwa kriteria 
Daubert tersebut berbeda, maka dilakukan voting untuk mencapai konsensus.

\section{Hasil dan Pembahasan}

Penelitian ini berawal dari belum adanya sebuah repository yang mendokumentasikan framework forensika digital. Framework forensika digital masih tersebar dalam berbagai paper, sehingga investigator harus mencari informasi framework forensika digital satu persatu. Ini tentunya tidak praktis dan menghambat investigator dalam memulai melakukan investigasi untuk sebuah kasus.

Data framework yang disimpan dalam repository antara lain:

a. Judul, yang menujukkan nama framework forensika digital. Jika tidak ada nama framework, maka dapat diisi dengan judul penelitian yang mengusulkan framework tersebut.

b. Abstrak, yang berisi uraian singkat mengenai framework forensika digital.

c. Author, yang berisi nama-nama peneliti yang mengusulkan framework forensika digital.

d. Tahun, yang menunjukkan tahun terbit jurnal yang mengusulan framework tersebut.

e. Jurnal, berisi daftar berbagai jurnal yang terkait dengan framework yang diusulkan. Jurnal yang menjadi acuan dari framework yang diusulkan perlu disebutkan.

f. Tahapan, berisi gambar yang menunjukkan tahapan proses investigasi forensika digital yang diusulkan oleh framewok.

g. PDF File, berisi file naskah publikasi dari penelitian yang mengusulkan framewok tersebut.

Informasi framework forensika digital yang lebih lengkap bisa dilihat di Detail Framework, sebagaimana ditunjukkan oleh Gambar 4.1.

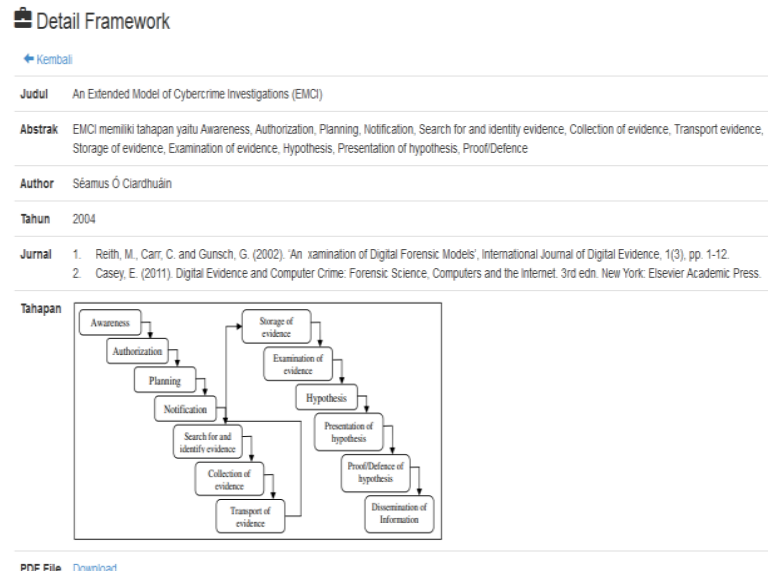

Gambar 4.1 Contoh Detail Framework dalam Repository Framework

Daftar framework forensika digital yang sudah ada kedalam repository, sebagaimana ditunjukkan oleh Tabel II.

TABEL II. DAFTAR FRAMEWORK DALAM REPOSITORY

\begin{tabular}{|c|c|c|}
\hline No & Judul & Author \\
\hline \multirow[t]{2}{*}{1} & Systematic Digital Forensic & Mr. Ankit Agarwal, Ms. \\
\hline & $\begin{array}{l}\text { Investigation Model } \\
\text { (SDFIM) }\end{array}$ & $\begin{array}{l}\text { Megha Gupta, Mr. } \\
\text { Saurabh Gupta, Prof. } \\
\text { (Dr.) Subhash Chandra } \\
\text { Gupta }\end{array}$ \\
\hline 2 & $\begin{array}{l}\text { Hierarchical, Objectives } \\
\text { Framework for } \\
\text { Investigation Digital } \\
\text { (HOBFDIP) }\end{array}$ & $\begin{array}{l}\text { Nicole Lang Beebe, } \\
\text { Jan Guynes Clark }\end{array}$ \\
\hline 3 & $\begin{array}{l}\text { An Extended Model of } \\
\text { Cybercrime Investigations } \\
(\mathrm{EMCl})\end{array}$ & Séamus Ó C \\
\hline \multirow[t]{2}{*}{4} & $\begin{array}{l}\text { A Common Process Model } \\
\text { for Incident Response and }\end{array}$ & $\begin{array}{l}\text { Felix C. Freiling, } \\
\text { Bastian Schwittay }\end{array}$ \\
\hline & $\begin{array}{l}\text { Computer } \quad \text { Forensics } \\
\text { (CPMIRCF) }\end{array}$ & \\
\hline 5 & $\begin{array}{lll}\text { Four Step } & \text { For } \\
\text { Process (FSFP) } & \end{array}$ & $\begin{array}{l}\text { Karen Kent, Suzanne } \\
\text { Chevalier, Tim Grance, } \\
\text { Hung Dang }\end{array}$ \\
\hline 6 & $\begin{array}{l}\text { Integrated Digital Forensic } \\
\text { Process Model (IDFPM) }\end{array}$ & Michael Donovan Kohn \\
\hline 7 & $\begin{array}{l}\text { Digital Evidence Cabinets } \\
\text { (DEC) }\end{array}$ & $\begin{array}{l}\text { Yudi Prayudi, Ahmad } \\
\text { Ashari, Tri K } \\
\text { Priyambodo }\end{array}$ \\
\hline 8 & $\begin{array}{l}\text { Computer Forensics Field } \\
\text { Triage Process Model } \\
\text { (CFFTPM) }\end{array}$ & $\begin{array}{lr}\text { Marcus K. } & \text { Rogers, } \\
\text { James Goldman, Rick } \\
\text { Mislan, } \\
\text { Wedge, Steve Debrota }\end{array}$ \\
\hline 9 & $\begin{array}{l}\text { Mapping Process of Digital } \\
\text { Forensic Investigation } \\
\text { Framework (MPDFIF) }\end{array}$ & $\begin{array}{l}\text { Siti Rahayu Selamat, } \\
\text { Robiah Yusof, Shahrin } \\
\text { Sahib }\end{array}$ \\
\hline 10 & $\begin{array}{l}\text { Abstract Digital Forensics } \\
\text { Model (ADFM) }\end{array}$ & $\begin{array}{l}\text { M. Reith, C. Carr dan } \\
\text { G. Gunsh }\end{array}$ \\
\hline 11 & The Integrated & B. Carrrier, E. Spafford \\
\hline
\end{tabular}




\begin{tabular}{|c|c|c|}
\hline & $\begin{array}{l}\text { Investigation } \\
\text { (IDIP) }\end{array}$ & \\
\hline 12 & $\begin{array}{l}\text { The Digital Forensics } \\
\text { Research Workshop Model } \\
\text { (DFRWS) }\end{array}$ & Palmer \\
\hline 13 & $\begin{array}{l}\text { A Forensic Framework for } \\
\text { Tracing Phishers }\end{array}$ & $\begin{array}{l}\text { Sebastian Gajek, } \\
\text { Ahmad Reza Sadegh }\end{array}$ \\
\hline 14 & $\begin{array}{l}\text { A Framework for the } \\
\text { Forensic Investigation of } \\
\text { Unstructured Email } \\
\text { Relationship Data }\end{array}$ & $\begin{array}{l}\text { John Haggerty, } \\
\text { Alexander J. Karran, } \\
\text { David J. Lamb, Mark J. } \\
\text { Taylor }\end{array}$ \\
\hline 15 & $\begin{array}{l}\text { A Proposed Digital } \\
\text { Forensics Business Model } \\
\text { to Support Cybercrime } \\
\text { Investigation in Indonesia }\end{array}$ & $\begin{array}{l}\text { Yudi Prayudi, Ahmad } \\
\text { Ashari, Tri K. } \\
\text { Priyambodo }\end{array}$ \\
\hline 16 & $\begin{array}{l}\text { Computer Forensic } \\
\text { Investigative Process }\end{array}$ & Politt \\
\hline 17 & $\begin{array}{l}\text { Enhanced } \\
\text { Investigation } \\
\text { Model (EDIP) }\end{array}$ & $\begin{array}{l}\text { V. Baryamereeba \& F. } \\
\text { Tushabe }\end{array}$ \\
\hline 18 & $\begin{array}{l}\text { Digital Forensic Model } \\
\text { based on Malaysian } \\
\text { Investigation } \\
\text { (DFMMIP) }\end{array}$ & $\mathrm{P}$ \\
\hline 19 & $\begin{array}{l}\text { End to End Digital } \\
\text { Investigation }\end{array}$ & P. Stephenson \\
\hline 20 & $\begin{array}{l}\text { Dual Data Analysis } \\
\text { Process (DDAP) }\end{array}$ & D. Bem \& E. Huebner \\
\hline 21 & $\begin{array}{l}\text { Network Forensic Generic } \\
\text { Process Model (NFGP) }\end{array}$ & $\begin{array}{l}\text { Emmanuel S. Pilli, } \\
\text { R.C. Joshi , Rajdeep } \\
\text { Niyogi }\end{array}$ \\
\hline 22 & $\begin{array}{l}\text { Evidence } \\
\text { Framework }\end{array}$ & $\begin{array}{l}\text { Abdullah AlShaikh, } \\
\text { Mohamed Sedky }\end{array}$ \\
\hline 23 & $\begin{array}{l}\text { Digital Forensic } \\
\text { Investigation Model }\end{array}$ & $\begin{array}{l}\text { Inikpi O. Ademu, Dr } \\
\text { Chris O. Imafidon, Dr } \\
\text { David S. Preston }\end{array}$ \\
\hline
\end{tabular}

Setelah data framework terisi, selanjutnya expert dapat melakukan evaluasi framework. Expert dapat memilih salah satu framework yang akan dievaluasi. Evaluasi dilakukan dengan mengisi Data dan Fakta, Argumen, Terpenuhi/Tidak untuk masing-masing kriteria Daubert.

Data evaluasi yang sudah diisi oleh expert sebelumnya tidak dapat langsung diolah, dan harus menunggu minimal ada dua expert lainnya untuk mengevaluasi framework yang sama. Setelah itu, dilakukan pengecekan apakah ada kriteria dengan hasil evaluasi yang berbeda, sebagaimana ditunjukkan oleh Gambar 4.2.

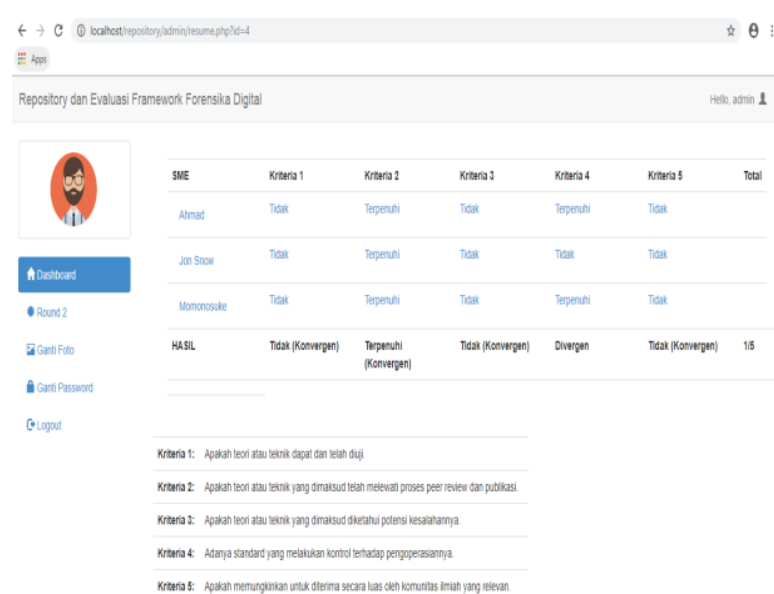

Gambar 4.2 Contoh Hasil Evaluasi Framework Round 1

Dari Gambar 4.2 diketahui bahwa dari tiga expert (Ahmad, Jon Snow, dan Momonosuke) mempunyai pendapat yang berbeda mengenai kriteria keempat, yaitu "Adanya standard yang melakukan control terhadap pengoperasiannya (the existence and maintenance of standards controlling its operation)". Expert Ahmad dan Momonosuke berpendapat bahwa framework tersebut sudah cukup memenuhi kriteria keempat, sedangkan expert Jon Snow berpendapat bahwa framework tersebut belum memenuhi kriteria keempat. Karena adanya perbedaan pendapat diantara expert (masih ada kriteria yang divergen), maka Admin memberikan notifikasi pada ketiga expert untuk memberikan evaluasi ulang khusus untuk kriteria keempat.

Selanjutnya, expert akan diarahkan ke menu Review Criteria untuk melakukan evaluasi ulang pada kriteria keempat, sebagaimana ditunjukkan oleh Gambar 4.3.

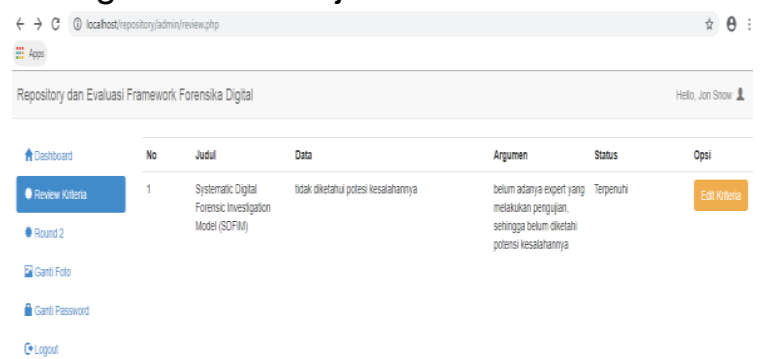

Gambar 4.3 Contoh Menu Review Kriteria 
Admin dapat melakukan pengecekan apakah semua expert sudah melakukan evaluasi ulang. Setelah Admin memastikan bahwa semua expert sudah melakukan evaluasi ulang, maka Admin akan melakukan pengecekan hasil evaluasinya. Jika semua expert mempertahankan evaluasi (yang berarti hasil evaluasi tidak berubah), maka Admin akan melakukan voting. Karena pada hasil evaluasi framework tersebut diketahui bahwa jumlah expert yang berpendapat bahwa framework memenuhi kriteria keempat dari Daubert (Terpenuhi vs Tidak = 2 vs 1 ), maka Admin membuat kesimpulan bahwa framework tersebut memenuhi kriteria keempat dari Daubert. Selanjutnya Admin menampilkan resume hasil evaluasi pada Dashboard.

Untuk contoh tersebut, dari resume hasil evaluasi diketahui bahwa hasil dari Daubert Scoring adalah 2/5. Artinya hasil konsensus menunjukkan bahwa framework tersebut memenuhi dua kriteria Daubert yaitu peer review dan standard control. Contoh hasil konsensus sebagaimana ditunjukkan oleh Gambar 4.4.

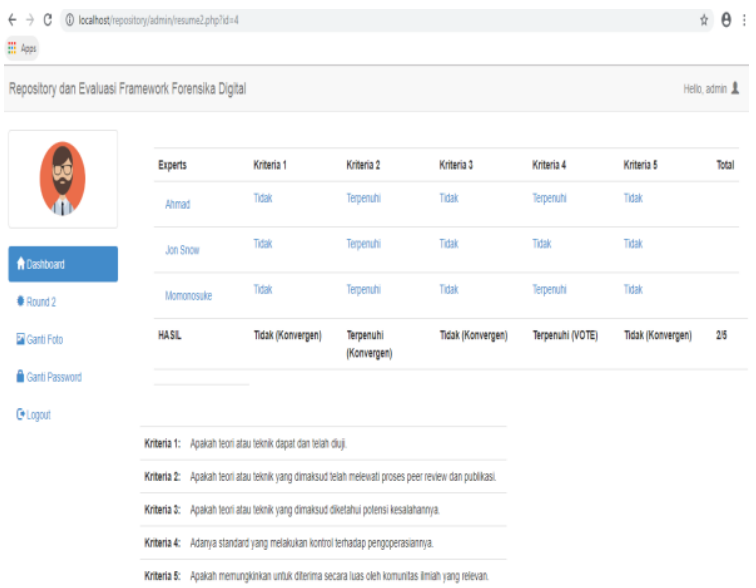

Gambar 4.4 Contoh Hasil Konsensus

\section{KESIMPULAN}

Pada penelitian ini telah dilakukan upaya untuk membangun repository melalui koleksi framework dari berbagai paper, lalu mendokumentasikannya dalam sebuah system. Selanjutnya evaluasi dilakukan framework yang diberikan oleh expert untuk masing-masing kriteria menggunakan Daubert Criteria. Pemahaman dari masing -masing expert akan sangat berpengaruh terhadap hasil review yang dilakukan. System yang dibangun telah memenuhi kebutuhan dalam hal repository framework karena memuat dokumen dan informasi penting dari framework pada bidang forensika digital.

\section{Daftar Pustaka}

Sremack,J. C., 2007. "The Gap Between Theory and Practice in Digital Foensics", in Coference on Digial Forensics, Security and Law, Arlington, Virginia, pp. 85-95.

Richter J. dan Kuntze N., 2010. "Securing Digital Evidence", in Fifth Iternationa Workshop on Systematic Approaches to Digital Forensic Engineering, Oakland, CA, USA, pp 110-130.

Schatz B., 2007. "Digital Evidence: Representation and Assurance". Queesland University of Technology.

Edward K. Cheng and Albert H. Yoon, "Does Frye or Daubert Matter? A Study of Scientific Admissibility Standards", Virginia Law Review Vol. 91, No. 2 (Apr., 2005), pp. 471-513

Montasari R., 2016. "Review and Assessment of The Existing Diitl Forensic Investigation Process Models", International Journal of Computer Applications.

Bernstein, D. E., \& Lasker, E. G., 2013. "Defending Daubert: it's time to amend Federal Rule of Evidence 702. William \& Mary Law Review", 57(2), 1-48.

Faigman, D. L., 2013. "The Daubert Revolution and the Birth of Modernity: Managing Scientific 
Evidence in the Age of Science", University of California Law Review, 46(1), 893-930.

Marcella, A. J, \& Greenfield, R. S. (Eds)., 2002. "Cyber Forensics: A Field Mannual for Collecting, Examining, and Preserving Evidence od Computer Crimes, Boca Raton, Florida: CRC Press Ltd.

Gary L Palmer., 2001. "A Road Map for Digital Forensic Research. Technical Report DTR-T0010-01, DFRWS", Report for the First Digital Forensic Research Workshop (DFRWS).

Adams R. B., 2012. "The Advanced Data Acquisition Model (ADAM): A Process Model for Digital Foensic Practice", Murdoch University. 